\title{
A role for football in mental health: the Coping Through Football project
}

\author{
Oliver J. Mason, ${ }^{1,2}$ Rebecca Holt ${ }^{1}$
}

The Psychiatrist (2012), 36, 290-293, doi: 10.1192/pb.bp.111.036269

${ }^{1}$ University College London; ${ }^{2}$ North East London Foundation NHS Trust

Correspondence to Oliver J. Mason (o.mason@ucl.ac.uk)

First received 11 Aug 2011, final revision 23 Apr 2012, accepted 9 May 2012

\begin{abstract}
Aims and method Coping Through Football aims to improve well-being and reduce social isolation for younger people with severe mental illness in a deprived area of North East London. Interviews were conducted with 12 service users, 5 referrers and 2 coaches to obtain their views of the project's implications for health and well-being, quality of life and social/community relationships. A qualitative approach was used to derive themes from interview transcripts using some of the tools of grounded theory.
\end{abstract}

Results Themes included: identifying with past self; service with a difference: opening up the social world; safety; empowerment; and feeling good. Coping Through Football was seen by stakeholders as leading to increased well-being and social opportunities within a safe and understanding environment.

Clinical implications For many service users the football project played a key role in their recovery of personal and social roles. Social and community-based mental health projects benefit greatly from active community collaboration, in this case a professional football club and several non-statutory sport/leisure bodies.

Declaration of interest None.
Growing evidence supports the use of physical activity interventions across a range of mental health problems; ${ }^{1}$ and has led to recommendations that exercise programmes should be an integral part of their management. ${ }^{2,3}$ How such interventions effect symptomatic and lifestyle change has not been extensively studied. Clinicians value empirical evidence about who is helped and how when making choices about patient care. Semi-structured qualitative interviewing of clinical psychologists about their perceptions of exercise ${ }^{4}$ revealed that although it is favoured as a lifestyle option, the lack of an explanation for clinical change reduced their willingness to consider it as a treatment. Quantitative studies have suggested a variety of physiological mechanisms as well as psychological factors such as self-efficacy, distraction and self-esteem playing a part. As an alternative to quantitative studies, Mutrie ${ }^{5}$ has suggested that qualitative methods may 'hold the key to a better understanding of the mechanisms underlying the effect of exercise on life quality' (p. 307). The current study applied qualitative methods to explore how one physical activity intervention based on football may lead to change for service users with severe/enduring mental health difficulties.

Coping Through Football (CTF) is a multi-agency collaboration between an east London professional football club, Waltham Forest Primary Care Trust (public health body), North East London NHS Foundation Trust (public health body), London Playing Fields Foundation (London charity), Capital Volunteering (London charity) and Sport England (national charity). The project was first conceived by the London Playing Fields Foundation, who initially liaised with the football club's community sports programme and local National Health Service (NHS) bodies. It was launched in May 2007 with the aim of improving mental health service users' physical and mental health, with additional emphasis from the start on improving social inclusion by enabling 'exit routes' into social and occupational activities based in the community. We aimed to understand service users', referrers' and professional coaches' views of the project's positive and negative implications for mental and physical health, quality of life and social and community relationships.

\section{Method}

Twelve male CTF attendees (Al-12: 20-45 years of age, mean age 28.2 years) were interviewed: none had employment when they took part in the project, although several have subsequently gained paid or voluntary roles; one was physically disabled. Ethnicity included five White, four African-Caribbean, one Indian, one Pakistani and one Bangladeshi participant. All had experienced recurrent psychotic and/or depressive illnesses and had care coordinators (assertive outreach team/community mental health team). Five referrers (R1-5) from local mental health services were also interviewed (a male consultant psychiatrist, two occupational therapists (one male, one female), two female assistant occupational therapists). Two male professional football coaches from the football club facilitate the group and were also interviewed (F1 and F2). The study was approved by the local NHS research ethics 
committee and all participants gave informed consent and were assured all identifying information would be confidential. The interview schedule was developed via review of the literature and extensive piloting.

Interview transcripts were analysed thematically ${ }^{6}$ using many of the tools of grounded theory ${ }^{7}$ (coding and memos). Independent coding of several transcripts provided a validity check of the themes and led to a good level of overall agreement. Although space precludes thorough description of methodology and reflexivity, this is available in the online data supplement. We do not avow that 'one size fits all' and have attempted to give a spread of the views and opinions offered by interviewees.

\section{Results}

Six themes were identified that were consistently important across the data-set. In every case these are illustrated by quotation, although space necessarily limits reporting to a small selection chosen to reflect each theme's content. Themes are not temporally sequential, and we are explicitly not presenting a linear narrative.

\section{Identifying with past self}

Playing football had been an important part of past lives and CTF offered a reconnection with a pre-illness identity. In particular, memories of football were strongly associated with enjoyment and a positive sense of self. Illness was often the reason they were no longer playing football and so playing again signified a return to health. One referrer summarised how important he thought this connection was:

'I think pretty much for most of the people that I have referred and have come have definitely played it in the past and want to start playing again because it's something that they associate with a happy time in their life.' (R1)

\section{Service with a difference}

Coping Through Football offered a very different experience to previously accessed services with explicit comparisons made to day care and psychotherapy. The main differences were that CTF was not problem focused and offered an opportunity for change and development.

'By coming to these sessions and identifying with other people, oh yeah, I have that, and then realising oh okay, we can all say that we've got mental health issues here but I'm not, so I'm not completely crazy. I've done groups and anxiety groups and stuff like that, but there's something different about football.' (Al)

'You know when clients turn up they don't see it as an NHS group or a mental health group. It's a football training group and that is a key ingredient'. (F1)

\section{Opening up the social world: breaking isolation, offering structure and friendship}

Attendees spoke about how coming to CTF had helped to 'break this isolation':

'Well I don't really communicate with anybody outside this [CTF] really. I speak to people on the internet and phone and stuff, but I don't really go out.' (A10)

All service users highlighted how their friendship network had expanded, sharing 'chit chat' around their teams' football scores and, for some, highly personal problems.
'It's just that they're [friendships] more, sort of, maybe a bit deeper, because we're not prohibited with what we can express ourselves with and talk about our problems that are not acceptable to society. The people I've met through here are my closest friends now. That's the best thing.' (A9)

'They [friendships] are honest, they're true, they're real. There is no pretence. I am what I am and if someone says, I'm not feeling comfortable, we all know okay, we all leave, do you know what I mean. I don't have to pretend that I'm completely happy. You can just be yourself, it's lovely, it's humanity.' (Al) 'We talk, a lot of different talking, and we joke . . . it's a very good atmosphere, a friendly atmosphere, if not a family. . From the way I see it here, everyone is very much open to the other one. So it's like a family in a way.' (A2)

For many, friendship extended beyond the CTF sessions to meeting up, attending football matches together and playing other sports.

\section{Psychological safety: self-expression, mutual support and belonging}

'You see once you're with a bunch of people that you know have got mental health issues, you feel much more comfortable with expressing yourself.' (A3)

A safe and supportive environment was one of the explicit aims of the project and facilitators described their efforts to achieve this. This can never ensure that individuals develop bonds and trust both with facilitators and one another. However, it was clear from participants' accounts that a feeling of safety and trust was something that developed over time as they started to identify with each other.

'I think at the beginning, people are very much personal, keeping if you like to themselves. They don't really talk about their problems ... . but as time goes by , people start to engage with other people even if they don't know them because they know that they are part ... they know they know that they are in the same basket if you like.' (A2)

Psychological safety was attributed by the referrers and attendees as being generated by the inclusive, welcoming nature of the participants towards each other, as well as the skills of the coaches, who made people feel comfortable and at ease, through their engaging, inclusive style. The medium of football contributed significantly - something very different to other therapies:

'You are allowed to shout and scream, you know, there's not someone telling you to be quiet because it's football and you're allowed to shout. If you shout or scream in an anxiety group, then the group leader tells you to be quiet. So it gives you that opportunity to let some steam off which is very important.' (A5)

'People put it down saying well all you do is play a game of football. I say to them. Look this isn't actually what we do here ... we're trying to bring them out of their shells as well and get their minds on other things and being around people and not thinking of doing drugs or anything like that you know, or feeling negative about themselves.' (A4)

'You see familiar faces . . . I feel like I'm part of a team and I kind of feel like, I almost feel like I fit in, and that's nice because I don't often feel like that.' (A6)

\section{'Feeling good': fitness, health and enjoyment}

Physical fitness and/or psychological gains were highlighted by all participants as key benefits of attending the project. Several emphasised weight loss - for some reversing some of the weight gain associated with medication. Over half mentioned football's role in helping them reduce or even 
stop smoking. They explained this came from a motivation to perform better and from noticing performance improvements over time. Most mentioned improvements to mood and motivation. The perceived benefits were described by referrers and coaches to be central to participants' sustained motivation to participate.

'A lot of the time, especially when I first came out of hospital, I wasn't doing much. I'd literally be watching telly in bed because I was so depressed, but I'd drag myself out to football so at least once a week I'd be doing a little bit of exercise.' (A6)

'I think I'm fitter. I definitely think I'm a bit slimmer, which is what I was hoping for.' (A3)

'You know it's amazing. I would intend every morning to get up and do some exercise, but I don't and because I have to come to football, I come, I do the exercise, I feel better. I spend the evening at home feeling much more relaxed and much more at ease with myself, motivated.' (All)

'It just makes you feel good inside, you know to score a goal. It makes you feel good running as well. There's something about running that makes you feel alive. It's like a sense of freedom to it.' (A3)

'It's saving some people from a life of drugs and sitting around all day smoking.' (Al)

\section{Empowerment: achieving, developing confidence, competing and moving on}

One of the strongest outcomes to emerge was increased selfconfidence/self-esteem and so we have chosen to highlight this as a theme in its own right although it was clearly linked to the previous theme. Importantly, participants gave us examples of how greater self-confidence had grown beyond the boundary of the football pitch.

'It makes me more confident all round, you know. My selfconfidence has gone up quite a bit in all walks of life. It's because I'm doing something that I enjoy. It's given me confidence on public transport and I used to feel shy and . . very withdrawn. And it's given me to confidence to come out and do things you know.' (A4)

'I get excited about games after I've played them. I've done something good in a match and I will actually replay it in my head. And actually, my heart starts beating faster thinking about these things . . . it's like a physical indication of my selfsteem.' (A11)

Experiences for some led to future plans and provided inspiration for other possibilities. Two service users spoke about how they had become ambassadors for the project and were actively involved in the CTF steering group and in helping other clubs start schemes. One coach added:

'Once they see their physical health improving, they start to come up with ideas about wanting to do other things, like people are saying to me, right football's great on a Tuesday and a Thursday, but I want to do a college course and . . . things that they maybe probably wouldn't have considered doing or maybe wanted to do and couldn't see themselves doing a year ago.' (F2)

\section{Discussion}

Enduring mental illness is often associated with the loss of a person's sense of self and previous held identity. A recent exploration of the impact of mental illness on a person's identity ${ }^{8}$ found that individuals with mental illness had 'severe challenges' managing their loss of identity after the onset of illness. The present results echo those of Carless \& Douglas ${ }^{9}$ in supporting the idea that participation in sports and exercise contributes to recovery by reinforcing one's identity and sense of self. The CTF project offered the opportunity for social interaction in the context of a normalising activity and helped reduce social isolation.

The supportive nature of CTF was universally endorsed, perhaps even more effectively for being implicit rather than explicit. Several categories are consistent with what Nelson et al call a support group: 'in which people with a common experience come together on a voluntary and equal basis to share their experiential knowledge and to provide and receive informal social support' (p. 889). ${ }^{10}$ We grouped a number of aspects together as 'empowerment' consistent with Dickerson's ${ }^{11}$ suggestion that this encompasses personal competence, self-determination and social engagement. With regard to social engagement, the findings suggest that participants were identifying with and validating each other, a first step in the process of social engagement according to Dickerson. A central component of self-determination is that people are actively able to make personal life decisions and choices about their involvement in their treatment and rehabilitation.

Although the scheme is conceived partly in terms of increasing social capital and inclusion, few comments from participants themselves explicitly reflected this. Although not the focus here, many have left the programme to pursue educational or vocational opportunities and it is perhaps a wider awareness of this fact that is reflected in some comments by referrers and facilitators. As participants were still taking part in the scheme, their comments perhaps understandably predominantly reflect the safety and understanding they perceive as so central to the project. These features may well be necessary precursors to these participants venturing into social contexts beyond the project.

Clinicians referring to CTF were universally positive and considered it as a core plank in care plans, rather than an 'optional extra'. By attending the project themselves, many made observations about the psychological and social mechanisms by which change occurred. The participatory and, indeed, physically involving elements of this activity contributed to their perceptions of its benefits. As enthusiasm took hold many participants became intrinsically motivated to attend for 'fun', social contact and to improve their skills. As participants reported back to referring clinicians, they saw this evidence with their own eyes and the project has seen ever growing referral rates as word of mouth spreads this message.

An important caveat is that only a subsample of the schemes' attendees was interviewed and it is very possible that the totality of experiences and views have not been garnered. Others who did not take up on the scheme were not interviewed and thus reasons for non-attendance were not elucidated. Although the sample was broadly representative of the age and ethnicity of scheme attendees as a whole, others were not represented including but not limited to females, those of mixed ethnicity or with physical disability, all of whom are statistically rare but important to the diversity of its intake.

Now an enduring feature in east London, there are plans to replicate CTF's success at several other major football clubs - indeed one former service user of the scheme now facilitates Arsenal Football Club's scheme run along similar lines. 


\section{About the authors}

OliverJ. Mason is a senior lecturer at the Research Department of Clinical, Educational and Health Psychology at University College London, and Deputy Director of Research and Development, North East London NHS Foundation Trust. Rebecca Holt is a clinical psychologist at the Research Department of Clinical, Educational and Health Psychology at University College London, UK.

\section{References}

1 Biddle S, Fox K, Boucher S. Physical Activity and Psychological Well-Being Routledge, 2000

2 Grant T. Physical Activity and Mental Health - National Consensus Statements and Guidelines for Practitioners. Health Education Authority, 2000

3 Biddle S, Mutrie N. Psychology of Physical Activity Determinants, WellBeing and Interventions. Routledge, 2001.

4 Faulkner G, Biddle S. Exercise and mental health: it's not just psychology! J Sports Sci 2001; 19: 433-44.
5 Mutrie N. The therapeutic effects of exercise on the self. In The Physical Self: From Motivation to Well-Being (ed. KR Fox): 287-314. Human Kinetics, 1997.

6 Braun V, Clarke V. Using thematic analysis in psychology. Qual Res Psychol 2006; 3: 77-101.

7 Strauss A, Corbin J. Basics of Qualitative Research Techniques and Procedures for Developing Grounded Theory. Sage, 1998.

8 Wisdom JP, Bruce K, Saedi GA, Weis T, Green CA. 'Stealing me from myself': identity and recovery in personal accounts of mental illness. Aust N Z J Psychiatry 2008; 42: 489-95.

9 Carless D, Douglas K. The role of sport and exercise in recovery from mental illness: two case studies. Int J Mens Health 2008; 7: 139-58.

10 Nelson G, Ochocka J, Griffin K, Lord J. 'Nothing about me, without me': participatory action research with self-help/mutual aid organizations for psychiatric consumer/survivors. Am J Community Psychol 1998; 26 $881-912$

11 Dickerson FB. Strategies that foster empowerment. Cogn Behav Pract 1998; 5: 231-9.

\title{
A two-model integrated personality disorder service: effect on bed use
}

\author{
Barry Jones, ${ }^{1}$ Georgia Juett, ${ }^{1}$ Nathan Hill ${ }^{1}$
}

The Psychiatrist (2012), 36, 293-298, doi: 10.1192/pb.bp.111.036384

${ }^{1}$ Touchstone Centre, South London and Maudsley NHS Trust, London, UK Correspondence to Barry Jones (barry.jones@slam.nhs.uk)

First received 10 Aug 2011, accepted 27 Jan 2012
Aims and method To assess the impact on psychiatric in-patient bed use of a new personality disorder service that uses two psychoanalytical models: mentalisationbased treatment (MBT) and the service user network (SUN). The number of psychiatric bed days used by patients attending each of the three arms of the service model (SUN, 3-day MBT, 2-day MBT) was collated using the electronic patient records system. Bed use in the 6 months and 12 months before each patient started treatment was compared with bed use in the same periods after starting treatment.

Results Overall, statistical analysis revealed bed use to be significantly reduced by 6 months of treatment, and the reduction continued to prove significant at 12 months. Comparison between subgroups found no significant difference in bed use between patients attending the MBT programme and patients attending the SUN project at 6 months, but patients on the 3-day MBT programme exhibited a significantly greater reduction in bed use at 6 months compared with patients on the 2-day MBT programme.

Clinical implications Intervention had a statistically significant effect overall on reducing bed use, which we suggest is linked to an improvement in patients' functioning, and is maintained at 6 months and 12 months of treatment. The lacking difference between the SUN and MBT components of the model raises questions regarding the best allocation of resources and the longer-term effects on bed use, to be answered by further study.

Declaration of interest None.
The diagnosis of personality disorder covers a wide range of conditions with disparate presentations. Given the plurality of approaches, the limited evidence base and the overlap between models, choosing an approach is difficult. In response to this, the National Personality Disorder Development Programme undertook an evaluation of 11 pilot 